\title{
I'm still proud to be a doctor, Mr Kennedy
}

\author{
Eric Wilkes Department of Community Medicine, University of Sheffield, Sheffield
}

\section{Editor's note}

The author, a professor of general practice and a practising GP, agrees with some of Kennedy's criticisms but argues that the problems he outlines are not for the most part the fault of the medical profession. Doctors, he suspects, are being cast in the role of scapegoats for the deep and complex disturbances afflicting our 'shop-soiled society'.

Samuel Johnson could use words but not always mince them. On one occasion he said a manuscript contained matter that was good and original, but unfortunately what was good was not original and what was original was not good. One is tempted to say this of the Reith Lectures. For all the genuineness of the case and the occasional insights, it is mostly warmed-up Illich in the end.

First of all one accepts that the National Health Service is a grossly over-professional service, that it is grotesquely and excessively hospital-based, increasingly irrelevant to the needs of the community, and showing a vastly greater capacity for expanding its costs rather than its effectiveness. This has been said by many doctors for many years and a pretty devastating indictment it makes. But do not blame the doctors for all of it.

We are not, God help us, blameless; yet even Ian Kennedy finds it easier and more convenient to take some of his more striking examples from the American scene. Karen Quinlan is not typical of British medicine and could it not be that the American Psychiatric Association was trying to protect homosexuals who were being ordered to have treatment, trying to shield them from the crude and overbearing judgments of their society, by saying they were not ill? And it is fair to say that some of the eccentricities, to British eyes, of American medicine are due to its uniquely malodorous lawyers combined with a consumerism so truculent and badly briefed that it gives many of us - but not apparently the Reith lecturer - pause.

There are issues mentioned in the beginning of the first lecture that are indeed troubling - but they won't go away. Heart transplants are probably more popular with the public than with the doctors, the selective treatment of handicapped newly-born babies has to be decided by someone or greater harm can ensue. And although one must sensitively brief the parents and involve them in the decision- making, to ask deeply distressed parents themselves to make these decisions is an improper abdication of responsibility. Doctors are deeply involved in these decisions not because they want to be but because they have to be; it is part of the professional commitment. The process should include input usually from both family and other professional colleagues. It is not perfect but is infinitely superior to the ghastly fantasy of some on-call committee including a local clergyman and a representative of the community health council.

If illness is a judgmental term, the doctors do not say people are ill nearly as often as the patients. That is why sick-note certification over the last quartercentury has gone up by 30 per cent, but in 'backward' less industrialised areas like East Anglia by only some five per cent. It is not just a medical decision that trivial illnesses present increasingly in a society less tolerable by the year. It is a sociological and not a medical phenomenon that fewer consultations are needed per episode of 'illness'. Being ill may indeed be at times more of a profitable status than a handicap, but don't blame us. Many of us connive, for we have little choice: but in the name of Beveridge, we did not create.

Don't blame the doctors again for morosely prescribing tranquillisers for all kinds of nonmedical desperation. We know many of our patients may be more unhappy than ill, but that will not hinder them from alcoholism or baby-battering or suicide; and what is supposed to follow from Kennedy's claim that by trying to help the doctor 'prevents the rancour she feels from being expressed in political or social terms'? If you are an overworked and ill-educated woman battling with the day's chores at a time when the prevailing dogma seems even less relevant and helpful than the doctors, which demonstration should you join?

Remember too, the drug firm's adverts took us in a bit as well. We really believed 10 or 15 years ago that the pills might help. Now we realise some I5 per cent of hospital admissions are due to drug reactions, we are trying to prescribe less, but the patients besiege us like South American peasants wanting their ration of coca leaves. We admit our past mistakes but that does not make them vanish.

And while we are on this theme, please do not quote to us that useless and discredited WHO rubric about 'total physical, mental and social well-being'. It does not and will not exist and we 
are, as doctors, far more interested in the maintenance of independence than with that sort of centrally heated rhetoric.

Of course, some of Kennedy's arguments ring true. Cholera and TB were killed off by improved sewage disposal, water supplies and housing - as the doctors have said - rather than by antibiotics. But do not take all the credit away from us. Polio used to exist even where hygiene was very good, diabetes is not treated with better water supplies, and the rubella immunisation campaign is sophisticated modern medicine at its best. On the other hand the recent increase in whooping cough morbidity and mortality is due to public intervention and consumerism at its worst.

One has to accept that the humilating depersonalisation of admission procedures, the cattle-market of out-patients, the diagnostic orientation of junior doctors can lead to 'the disease is what has to be treated, not the person'. We are seriously trying to remedy this but bankruptcy and other health professions do not always help. Great changes, such as in attitudes to the dying, are in hand but they may be slower to appear in a London teaching hospital, even in such a fine one as King's.

Indeed, an office in such an institution is not a good base for checking on the vocational training schemes for general practice that are transforming basic professional attitudes at great speed, and although the doctor may see himself as a scientist, his first career choice as a final year medical student is most commonly - by an embarrassingly wide margin - for the less scientific activities of general practice.

The power does indeed remain with the hospitals, which though they see themselves as grossly underresourced and hard-pressed seem to outsiders like Ian Kennedy and myself vastly over-capitalised and due for swingeing cuts. Empires, even the British, take time to fade and the hospital empire will shrink gradually as it prices itself out of the market. Yet although this may be both inevitable and right, it seems to me that the finest achievement of the first decades of the NHS has been the up-grading of our peripheral hospitals so that high-quality medicine can be so routinely encountered in our market towns that it is merely taken for granted.

And if overseas trainees go home and try and copy our research institutes, this is, surprisingly to Ian Kennedy, again not the doctors' fault. We would prefer that they had hygienists rather than doctors, but it is their politicians who insist on lavish schools of medicine, and if some of these happen to be medical politicians, we did not make it so.

To some degree now, we are all in the predicament of developing countries. We can no longer afford all the treatment that is theoretically available for personal health care, and although medical structures have been determined by the now bygone problems of acute infections, we are less equipped than ever to deal with the justifiable malaise associated with an unsatisfying and despoilegd environment. But this is a new problem to us, and we need more time to adjust. Geriatrics after all is le्कु than 50 years old.

Also, of course, we grossly neglect the chrorif disabled, the old and the mad. Kennedy may regayd 'the disease approach to mental illness as untenabl $\vec{\Phi}$ : but if he had seen the senile dement throwing her faeces at her daughter or the mother with puerpefal depression in grave danger of self-harm yet coping beautifully with her baby a few months later, the would surely accept that the curable/incurabfe dichotomy makes the disease approach a reasonabte, if imperfect, working model. In a sick society, when not to be well is normal, attitudes and resources will need changing among the doctors, but if we get too far away from our culture we would be in danger off even more arrogant ineffectiveness.

We admittedly neglect preventive medicine but this too is showing signs of change. If the Americams can cut down their coronary death rate as they have, so in the next decade will we-and probabify without the tremendous scale of profitable by-p s surgery for which they are paying. But - and thins point may not be emphasised in the middle-aged and discrete Fabianism of the Black ReportInequalities in health (I) - preventive medicine is gt its most difficult where it is most essential. Cerviegl smears are at their most useful for sixteen-year-ofd prostitutes who are not given to routine checs. Smoking and drinking, like drug overdoses a abuse, are commonest in the deprived areas of big cities: but if you give an ordinary unskillogd Glaswegian more money it is likely to be translated into more fags and booze and his cancer rate añ. his death rate - exceptionally high - will still be high not because he is poor but because his undegtstanding is poor, his imagination limited, his capacity to learn by reading of other people्. experiences is ill-developed, and his behaviourpattern is set more in concrete than that of the gin-swelling and by no means over-percepto company director who now watches his weight and smokes only cigars. In the turmoil of ceaseless change, the injustices and inadequacies are not 1 the doctor's fault.

When Ian Kennedy gets on to medical ethics, may well be on firmer ground. We agree at onfse that 'medical ethics are not separate from but part of the general and ethical order by which we live'. The snag is that in our shop-soiled society prevailing anomie, the preoccupation with costeffectiveness and self-fulfilment, make us as ta profession remarkably exposed.

Most parents would be keener than most of $\underset{\mathbb{Q}}{\mathbb{Q}} \mathrm{s}$ doctors to have a baby who would never wagk, never have control of bowels or bladder, who woutd be retarded and die fairly soon anyway, put quicky 


\title{
Medical mismanagement or patient vacillation?
}

\author{
P N Bamford Academic Department of Obstetrics and Gynaecology, The Middlesex Hospital, London
}

\begin{abstract}
Author's abstract
Ian Kennedy extols the virtues of self-determination by patients: they should make their own decisions about medical treatment after being given advice by their doctors; for doctors to make such decisions on their patients' behalf is authoritarian and unacceptable (I).

I present a case where, despite thorough consultation and counselling, the decisions made by the patient and supported by her doctors were found to be consistently inappropriate to her changing lifestyle.
\end{abstract}

\section{Case report}

Mrs A C first presented at the age of 32 requesting reversal of sterilisation. She had married at 18 years, had four children over the next five years and had been sterilised one year later. Her marriage ended in divorce three years after this when she was 27; she formed a new relationship and after a further five years requested reversal of sterilisation. She was seen with her partner by a senior gynaecologist at two different hospitals (she was referred from the first in view of a long waiting list). With some reservations both agreed that her request was reasonable. Unfortunately she had developed an atypical cervical smear and underwent the operation of cone biopsy. As a result there was a further delay of 18 months prior to tubal re-anastomosis to reverse her sterilisation.

The patient presented again two years later with excessive bleeding and requested a hysterectomy. Her second marriage had by this time ended partly, she claimed, due to her failure to conceive.

Continued at bottom of page $I 8 \mathrm{I}$
Continued from page 178

to sleep. The doctors have made tremendous adjustments - some would say excessively so - in implementing the responsible but minor controls of abortion demanded of us by our society. The ethical decisions may be indeed haphazard and idiosyncratic but this is precisely because we are part of a haphazard and idiosyncratic society. The similarities in birth control practices of Catholic and non-Catholic populations in Western Europe show the strength of societal pressures.

When we get on to informing the patient, attitudes again are changing. Thirty years ago most patients were content to let the doctors do as much as possible of their worrying for them. Now with the diminished status of doctors (partly overdue in an egalitarian society, partly explicable via the sociology of envy) we are trusted less and are required to tell more. We try our best but some of us will be brutal and some evasive. There is however good, if anecdotal, evidence that we are increasingly being as honest and at the same time as kind with our patients as we can manage: and I am perpetually being humbled yet inspired by the courage and humour of our patients, when one shares a difficult situation with them.

Although they loom closer, we have not yet got a clinical ombudsman, clinical audit is not yet routine, informed consent difficult to achieve, and litigation may well prove a more effective education tool than the post-graduate lecture. Some doctors may be conservative, dedicated to the concealment of their ignorance, dogmatic, selfish, unimaginative and even paranoid. Yet as a profession we have exposed ourselves to over-production of doctors, unemployment and redundancy; we have accepted one of the lowest living standards of doctors in Western Europe; and except in the city centres we work harder and die quicker - we do try.

We may be greedy-irreverent registrars once demonstrated a positive correlation between the length of the consultant's car and the length of his NHS waiting list-but we are still dedicated, intelligent, and as incorruptible a crowd as you will meet anywhere, so that although the doctors are ghastly at times, I am still proud to be one of them. Some teaching hospitals may resemble 'hermetically sealed cocoons' but if we are all that isolated, could it be that we are sometimes more sinned against than sinning, more victim or target rather than mass manipulator?

To me at any rate this seems likely. It is no excuse, but there are more dishonourable roles than scapegoat.

\section{Reference}

(I) Inequalities in health. (The Black Report). London: DHSS, 1980. 